\title{
The challenge of defining wellbeing
}

\author{
Rachel Dodge · Annette P. Daly • Jan Huyton · Lalage D. Sanders
}

\begin{abstract}
Wellbeing is a growing area of research, yet the question of how it should be defined remains unanswered. This multi-disciplinary review explores past attempts to define wellbeing and provides an overview of the main theoretical perspectives, from the work of Aristotle to the present day. The article argues that many attempts at expressing its nature have focused purely on dimensions of wellbeing, rather than on definition. Among these theoretical perspectives, we highlight the pertinence of dynamic equilibrium theory of wellbeing (Headey \& Wearing, 1989), the effect of life challenges on homeostasis (Cummins, 2010) and the lifespan model of development (Hendry \& Kloep, 2002). Consequently, we conclude that it would be appropriate for a new definition of wellbeing to centre on a state of equilibrium or balance that can be affected by life events or challenges. The article closes by proposing this new definition, which we believe to be simple, universal in application, optimistic and a basis for measurement. This definition conveys the multi-faceted nature of wellbeing and can help individuals and policy makers move forward in their understanding of this popular term.
\end{abstract}

Keywords: definition, equilibrium, challenges, resources

\section{Introduction}

Research in wellbeing has been growing in recent decades (e.g., Diener, Suh, Lucas, \& Smith, 1999; Kahneman, Diener, \& Schwarz, 1999; Keyes, Schmotkin, \& Ryff, 2002; Stratham \& Chase, 2010; Seligman, 2011). However, very early on in the research Ryff and Keyes (1995) identified that "the absence of theory-based formulations of well-being is puzzling" (pp. 719-720). The question of how wellbeing should be defined (or spelt) still remains largely unresolved, which "has given rise to blurred and overly broad definitions of wellbeing" (Forgeard, Jayawickreme, Kern, \& Seligman 2011, p. 81). This deficit can be traced back as far as Ryff (1989a), who believed that "there has been particular neglect ... [in] the task of defining the essential features of psychological wellbeing" (p. 1069). Indeed, Thomas (2009) argued that wellbeing is "intangible, difficult to define and even harder to measure" (p. 11).

A theme that will run through this paper is the difference between the 'description' of a construct and its 'definition'. As interest in the measurement of wellbeing grows, there is a greater necessity to be clear about what is being measured, and how the resulting data should be interpreted, in order to undertake a fair and valid assessment. Therefore, any new definition must go beyond an account or description of wellbeing itself, and be able to make a clear and definite statement of the exact meaning of the term. Consequently, the aim of this paper is to propose a definition of what constitutes wellbeing: "a complex, multi-faceted construct that has continued to elude researchers' attempts to define and measure" (Pollard \& Lee, 2003, p. 60). 


\section{The historical background to wellbeing research}

Knowing the historical background to the study of wellbeing is necessary to the definition of wellbeing. Two approaches emerged: the hedonic tradition, which accentuated constructs such as happiness, positive affect, low negative affect, and satisfaction with life (e.g., Bradburn, 1969; Diener, 1984; Kahneman, Diener, \& Schwarz, 1999; Lyubomirsky \& Lepper, 1999); and the eudaimonic tradition, which highlighted positive psychological functioning and human development (e.g., Rogers, 1961; Ryff, 1989a; 1989b; Waterman, 1993). However, despite the differences in approach, most researchers now believe that wellbeing is a multi-dimensional construct (e.g., Diener, 2009; Michaelson, Abdallah, Steuer, Thompson, \& Marks, 2009; Stiglitz, Sen, \& Fitoussi 2009). Consequently, the diversity of dimensions has created a "confusing and contradictory research base" (Pollard and Lee, 2003, p. 2).

An early attempt to define wellbeing was Bradburn's (1969) classic research on psychological wellbeing. His work marked a move away from the diagnosis of psychiatric cases to the study of psychological reactions of ordinary people in their daily lives. His discussion stemmed from his interest in how individuals coped with the daily difficulties that they faced. Bradburn highlighted how psychological wellbeing (which he also referred to as happiness) was the variable that "stands out as being of primary importance" (p. 6). He linked this to Aristotle's idea of eudaimonia, which is now more commonly translated as wellbeing. Aristotle believed this to be the overarching goal of all human actions. The majority of Bradburn's research focused on the distinction between positive and negative affect. His model specified that:

an individual will be high in psychological well-being in the degree to which he has an excess of positive over negative affect and will be low in well-being in the degree to which negative affect predominates over positive (Bradburn, 1969, p. 9)

\section{What constitutes wellbeing?}

Although Ryff (1989a) criticised Bradburn's work for not defining the basic structure of psychological wellbeing, an emphasis on positive and negative affect has been central to the work of Diener and Suh (1997). They believed that:

subjective well-being consists of three interrelated components: life satisfaction, pleasant affect, and unpleasant affect. Affect refers to pleasant and unpleasant moods and emotions, whereas life satisfaction refers to a cognitive sense of satisfaction with life (Diener \& Suh, 1997, p. 200)

Headey and colleagues (Headey, Holmstrom, \& Wearing, 1984a; 1984b; Headey, 2006) picked up on the need for positive and negative affects to be seen as distinct dimensions, rather than opposite ends of the same continuum (Bradburn, 1969) as they are "only moderately negatively correlated" (Headey, 2006, p. 2). This was more recently supported by Lee and Ogozoglu (2007) and Singh and Duggal Jha (2008).

Ryff's early work (Ryff, 1989a) identified aspects that constitute wellbeing: autonomy; environmental mastery; positive relationships with others; purpose in life; realisation of potential and self-acceptance. More recent research has placed different emphases on what wellbeing is: ability to fulfil goals (Foresight Mental Capital and Wellbeing Project, 2008); happiness (Pollard \& Lee, 2003) and life satisfaction (Diener \& Suh, 1997; Seligman, 2002a). However, again, this highlights the problem that researchers have focused on dimensions or descriptions of wellbeing rather than on definitions (Christopher, 1999). 
Over 30 years ago, Shin and Johnson (1978) seemed to move closer to defining wellbeing by stating that it is "a global assessment of a person's quality of life according to his own chosen criteria" (p. 478) and this judgement is still reflected in today's literature (Zikmund, 2003; Rees, Goswami, \& Bradshaw 2010; Stratham \& Chase, 2010). But what, exactly, is "quality of life"?

The World Health Organization defined quality of life as:

an individual's perception of their position in life in the context of the culture and value systems in which they live and in relation to their goals, expectations, standards and concerns. It is a broad ranging concept affected in a complex way by the person's physical health, psychological state, personal beliefs, social relationships and their relationship to salient features of their environment (World Health Organization, 1997)

This emphasis on achieving goals reflects the work of Emerson (1985) and Felce and Perry (1995), who believed that wellbeing stems from individuals' perception of their current situation and their aspirations.

However, a problem with the term 'quality of life' is that it is used interchangeably with 'wellbeing' in a variety of disciplines. Many believe that this has made the task of defining wellbeing "conceptually muddy" (Morrow \& Mayall, 2009, p. 221). However, Stratham and Chase (2010) argue that the term wellbeing has enabled psychologists to 'de-medicalise' (p. 5) the concept of health. Consequently, it is now possible to consider quality of life separately from ideas of illness. This neatly reflects the seminal work of Herzlich (1973), who placed great emphasis on the attitude of the individual towards health, very like the current emphasis of wellbeing research using subjective wellbeing measures. Herzlich explained how health can be viewed in both a positive and negative light. Firstly, it can be seen as an "absence of illness" (p. 53). Indeed, she discussed how individuals might not notice health until something affects it. On the other hand, Herzlich proposed that health can be seen in a positive light "as a presence of which one is fully aware because of one's feelings of freedom and of bodily and functional well-being" (p. 53).

Another useful point made by Herzlich is how important it is to define "what constitutes normality" (p. 55). However, she admitted that normality was very difficult to evaluate. This difficulty of reaching a definition of normality also reflects the current problem of attempting to define wellbeing. Herzlich believed just identifying an "absence of illness" was inadequate in terms of defining normality. Furthermore, she suggested that "some writers have insisted that it may be futile to try to treat health as a single concept" (p. 55). This view is reflected in a recent article by Forgeard and colleagues (2011), who propose that:

some researchers have preferred to ignore the multifaceted nature of wellbeing and equate it with one construct (often life satisfaction), leading to the unfortunate omission of other important aspects of wellbeing (p. 81)

Consequently, it seems that a narrow emphasis on quality of life cannot adequately help us to define wellbeing. Indeed, it would seem that quality of life appears to be a dimension of wellbeing rather than an all-embracing definition.

The focus on positive functioning that has attracted increased attention in the past few years (Duckworth, Steen, \& Seligman, 2005; Linley \& Joseph, 2004; Linley, Joseph, Harrington, $\&$ Wood, 2006) dates back to William James' writings on healthy mindedness (James, 1902), and spans nearly 60 years to the work of Rogers (1961), who discussed wellbeing in terms of "the good life" (p. 186). He believed that each individual strived towards becoming a "fully functioning person" who is open to experience, is trusting in his/her own organism, and leads 
an increasingly existential life (Rogers, 1961, p. 187-189). His work has partly influenced the work of Ryff and Singer (2008) in their development of core dimensions of psychological wellbeing (PWB): self-acceptance; purpose in life; environmental mastery; positive relationships; personal growth; and autonomy.

An interesting development is the way in which this area of wellbeing has impacted on clinical psychology. Joseph and Wood (2010) have called for clinical psychology to adopt measures of positive functioning. This is because they believe that psychiatry has adopted a restricted view of wellbeing, seeing it as "an absence of distress and dysfunction" (p. 831). Therefore, the adoption of positive function would naturally broaden the field. They also believe that there is a possibility that this new slant on measurement will allow for prediction and treatment of distress and dysfunction. Research in this area has been undertaken by Keyes (2002; 2005), who views mental health as a syndrome of wellbeing symptoms. He believes that mental health is created "when an individual exhibits a high level on at least one symptom of hedonia and just over half the symptoms of eudaimonia, i.e., positive functioning in life" (Keyes, 2009, p. 15). In his 2002 research, Keyes asked youths to report the frequency of three symptoms of emotional wellbeing, four symptoms of psychological wellbeing and five symptoms of social wellbeing. Keyes made a "diagnosis of flourishing" if the individual displayed a third of the emotional symptoms, four of the psychological symptoms and five of the nine symptoms of positive flourishing "almost every day" or "every day" in the past thirty days.

The work of Keyes has led to the use of the terms 'flourishing' and 'languishing' as scientific concepts, rather than as philosophical ideals, as they had been previously presented (e.g., Griffin, 1986; Sumner, 1996; Hurthouse, 1999; Nussbaum, 2000). Keyes' work had a direct influence on the formulation of "a well-being manifesto for a flourishing society" by Shah and Marks (2004). This rather uplifting and encouraging document highlights that one of the key aims of any democratic government should be "to promote the good life: a flourishing society, where citizens are happy, healthy, capable and engaged - in other words with high levels of well-being" (p. 2). The manifesto goes on to clarify what Shah and Marks consider wellbeing to be:

Well-being is more than just happiness. As well as feeling satisfied and happy, well-being means developing as a person, being fulfilled, and making a contribution to the community $(2004$, p. 2)

Unfortunately, again, this appears to be more of a description of wellbeing rather than a definition.

The term 'flourishing' has now become synonymous with the positive psychology movement. Indeed, Gable and Haidt (2005) explain that "positive psychology is the study of the conditions and processes that contribute to the flourishing or optimal functioning of people, groups, and institutions" (p. 104). In a systematic examination of literature, Alkire (2002) noted 39 varying endeavours between 1938 and 2000 to define a 'flourishing' life.

The undeniable leader of the positive psychology movement is Martin Seligman. On the first day of his presidency of the American Psychological Society (APA) in 1998 he stated that:

I realized that my profession was half-baked. It wasn't enough for us to nullify disabling conditions and get to zero. We needed to ask, what are the enabling conditions that make human beings flourish? How do we get from zero to plus five? (Seligman, 1998, cited in Wallis, 2005, online) 
More than ten years on, Seligman has recently published his latest book entitled Flourish (Seligman, 2011), in which he outlines his new 'dynamic' concept of wellbeing, which moves away from theories based purely on happiness. The rationale behind this welcome departure from a now rather over-used term is because, according to Seligman (2011), the notion of 'happiness' is an awkward construct that hides the true, complex, nature of human flourishing.

He clearly states the rationale behind this change in direction:

I used to think that the topic of positive psychology was happiness... I now think that the topic of positive psychology is well-being, that the gold standard for measuring well-being is flourishing, and that the goal of positive psychology is to increase flourishing. (Seligman, 2011, p. 13)

Flourish discusses his theory with great clarity, but in terms of resolving the debate on defining wellbeing, it is disappointing. His 24-page chapter entitled 'What is Well-being?' fails to achieve its aim. In fact, Seligman states:

Well-being theory denies that the topic of positive psychology is a real thing; rather the topic is a construct - well-being - which in turn has several measurable elements, each a real thing, each contributing to well-being, but none defining well-being. (2011, p. 15)

Instead, his new theory of wellbeing concentrates, yet again, on elements of wellbeing which he believes are a set of building blocks for a flourishing life: Positive Emotion, Engagement, Relationships, Meaning, and Accomplishment (PERMA).

At this stage, the pursuit of a definition of wellbeing may appear bleak. However, we disagree with Seligman that wellbeing is a construct. This would imply that wellbeing is "not presently observable or objectively measurable but is assumed to exist because it ... gives rise to measurable phenomena" (Reber, 1995, p. 157). From the discussion so far, this obviously is not true. Instead, it is proposed that wellbeing should be considered to be a state - "a condition of a system in which the essential qualities are relatively stable" (Reber, 1995, p. 750).

\section{Equilibrium}

A theory that supports Reber's proposal is the dynamic equilibrium theory of wellbeing (now more often referred to as set-point theory). This was originally proposed 23 years ago by Headey and Wearing (1989) and suggested links between personality, life events, wellbeing and illbeing. The theory built on the work of Brickman and Campbell (1971), who had previously demonstrated that individuals tend to return to a baseline of happiness even after major life events.

Headey and Wearing continued to research their model $(1991 ; 1992)$ and believed that "for most people, most of the time, subjective well-being is fairly stable. This is because stock levels, psychic income flows and subjective well-being are in dynamic equilibrium" (1991, p. 49). This emphasis on equilibrium is not new and reflects, yet again, the work of Herzlich (1973). Her research emphasised that individuals saw equilibrium not only as a norm but also as a state that they would like to "attain or keep" (p. 59). Interestingly, in contrast to Headey and Wearing's idea that most individuals have stable wellbeing, Herzlich's interviewees saw it as a rare occurrence. However, Herzlich noted how often equilibrium was referred to by her participants and that it had a wide variety of applications. She found that the word "expresses a whole area of individual experience. It serves, in a way as a distillation of the language of health" (p. 59). She went further to fully explain what equilibrium is, in terms of health: 
Concretely, equilibrium comprises the following themes: physical well-being, plenty of physical resources; absence of fatigue; psychological well-being and evenness of temper; freedom of movement and effectiveness in action; good relations with other people. (Herzlich, 1973, p. 60)

The continued aim of Headey and Wearing's research has been to "understand how people cope with change and how their levels of well-being are affected" (1992, p. 6). They propose that a change in wellbeing occurs only when, due to external forces, "a person deviates from his or her equilibrium pattern of events" (1992, p. 93). Consequently, Headey and Wearing propose a definition of wellbeing in which wellbeing is shown "as depending on prior equilibrium levels of wellbeing and of life events, and also on recent events" (1992, p. 95). This reflects their framework for analysing subjective wellbeing (SWB), which considers the relationship between stocks and flows:

Figure 1. Headey \& Wearing's (1991) stocks and flows framework (p. 56)

\begin{tabular}{|c|c|c|}
\hline Stocks & Flows/psychic income & Subjective well \\
\hline 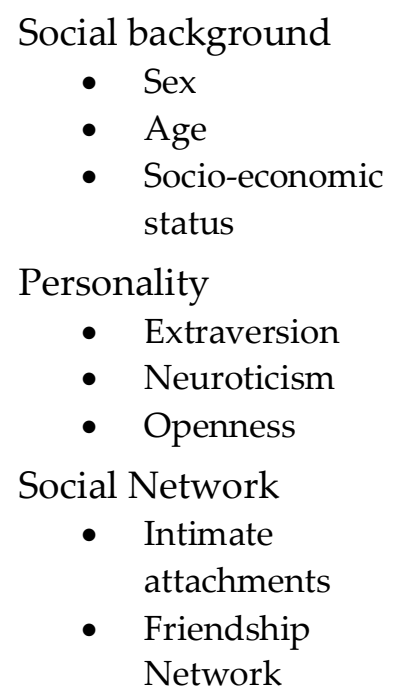 & $\begin{array}{l}\text { Favourable events } \\
\text { which yield } \\
\text { satisfaction } \\
\text { (income gains) } \\
\text { Adverse events which } \\
\text { yield distress } \\
\text { (income loss) }\end{array}$ & $\begin{array}{l}\text { Life Satisfaction } \\
\text { Positive Affect } \\
\text { Negative Affect }\end{array}$ \\
\hline
\end{tabular}

In this model, Headey and Wearing proposed that differences between individuals in terms of SWB are due to 'stable stocks' (otherwise known as stable personal characteristics). "As a result of stable stocks each person has a level of subjective wellbeing which represents his/her own "normal" equilibrium level" (1991, p. 57). Stocks are drawn upon to deal with specific life experiences ('flows') so that satisfaction is enhanced and distress is diminished. Consequently, "it is more appropriate to regard subjective well-being as a fluctuating state rather than a stable trait" (p. 56).

The theory has received much empirical investigation (Ormel \& Schaufeli, 1991; Ormel \& Wohlfaryh, 1991; Suh, Diener, \& Fujita, 1996). Suh and colleagues (1996) tested the dynamic equilibrium theory by tracking 222 psychology students (aged 20-21) during a transitional period of their life (which was their college graduation) and examined the effect of this life event on their SWB and the time it took these participants to adjust (to return to their state of equilibrium). Their findings supported the dynamic equilibrium model by demonstrating that 
"only recent life events influence SWB and that the impact of magnitude drops quickly afterward" (p. 1095). Consequently, in trying to define wellbeing, it is justified to consider the state of equilibrium as central.

\section{Challenges}

A more recent extension of this theory has been explored by Cummins (2010). Now the term 'equilibrium' has been replaced by 'homeostasis'; and the term 'life events' with the term 'challenge':

Figure 2. Cummins' Changing Levels of SWB

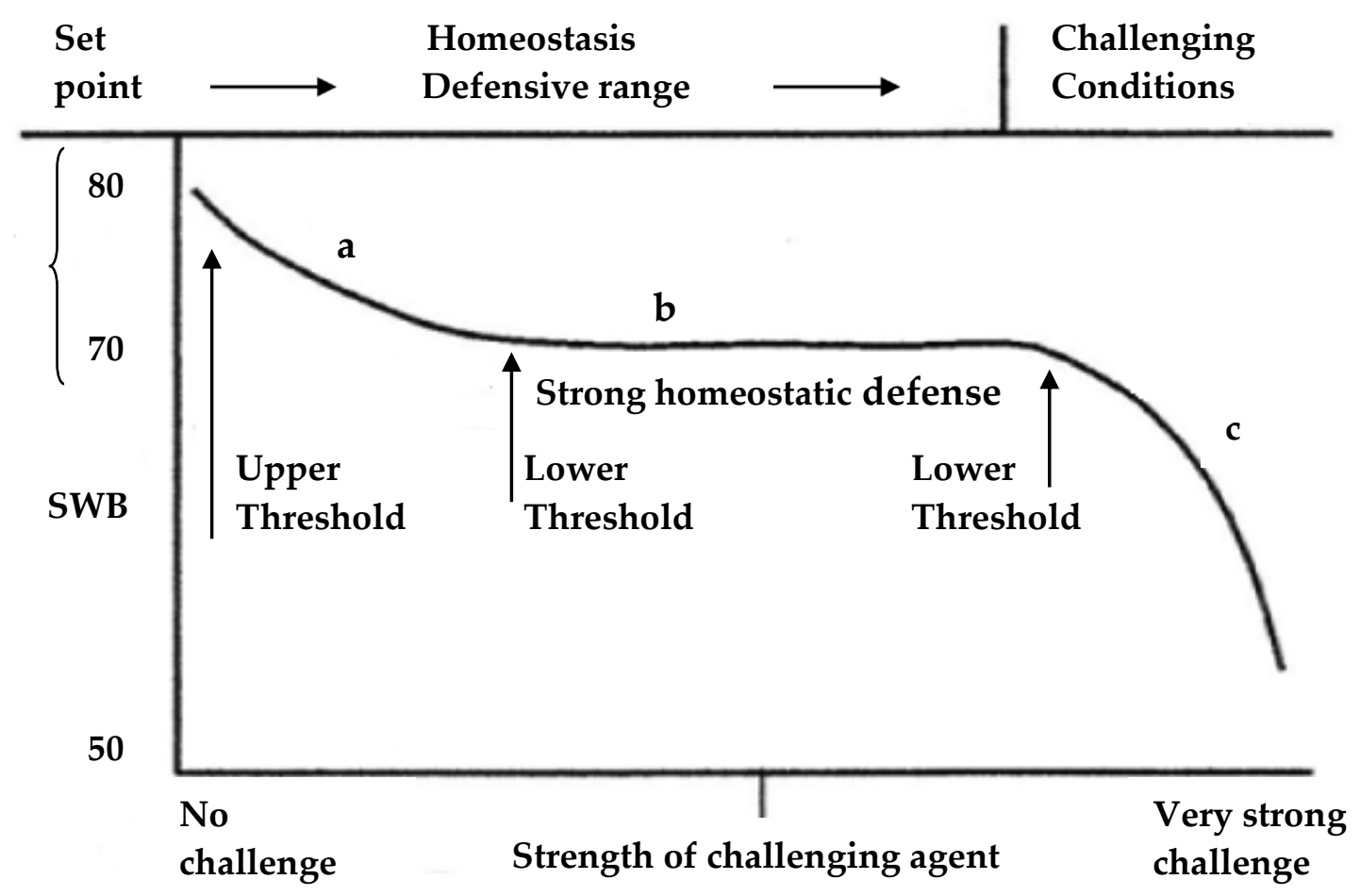

Cummins' theory focuses on the strength of a challenge and how this affects the level of SWB. This includes a derived set-point range (70 to 80 points) that was determined by previous research undertaken by Cummins (1995; 1998). The emphasis of the model is the role of homeostasis in defending the set point of SWB. The model may be a little confusing and complex at first glance. However, it tries to demonstrate different phases denoted by the letters 'a' to ' $c$ '.

- When an individual experiences no challenge, SWB stays at the set-point.

- When an individual experiences mild challenge, the level of SWB will vary slightly within the set-point range (Phase a)

- Phase b signifies where SWB is prevented from decreasing below the set point, due to the strong homeostatic defence.

- Phase c signifies a situation where the challenge is too strong for homeostasis to manage. SWB would now fall sharply.

Consequently, it would seem appropriate that any definition of wellbeing centres on a state of equilibrium or balance that can be affected by life events or challenges. 


\section{Resources}

Linked to challenges is the idea that each individual develops relevant skills or resources to cope with the trials they face. This balanced rationale between skills and challenges has been central to Mihaly Csikszentmihalyi's (1975) concept of 'flow' - "the state in which people are so involved in an activity that nothing else seems to matter" (2002, p. 4), which in turn leads to happiness. The original model assumed that enjoyment would happen when the strength of challenge and skills were both very low as well as when they were both high, as demonstrated in the following diagram:

Figure 3. Demonstration of the relationship between challenges and skills (Csikszentmihalyi, 2002, p. 74)

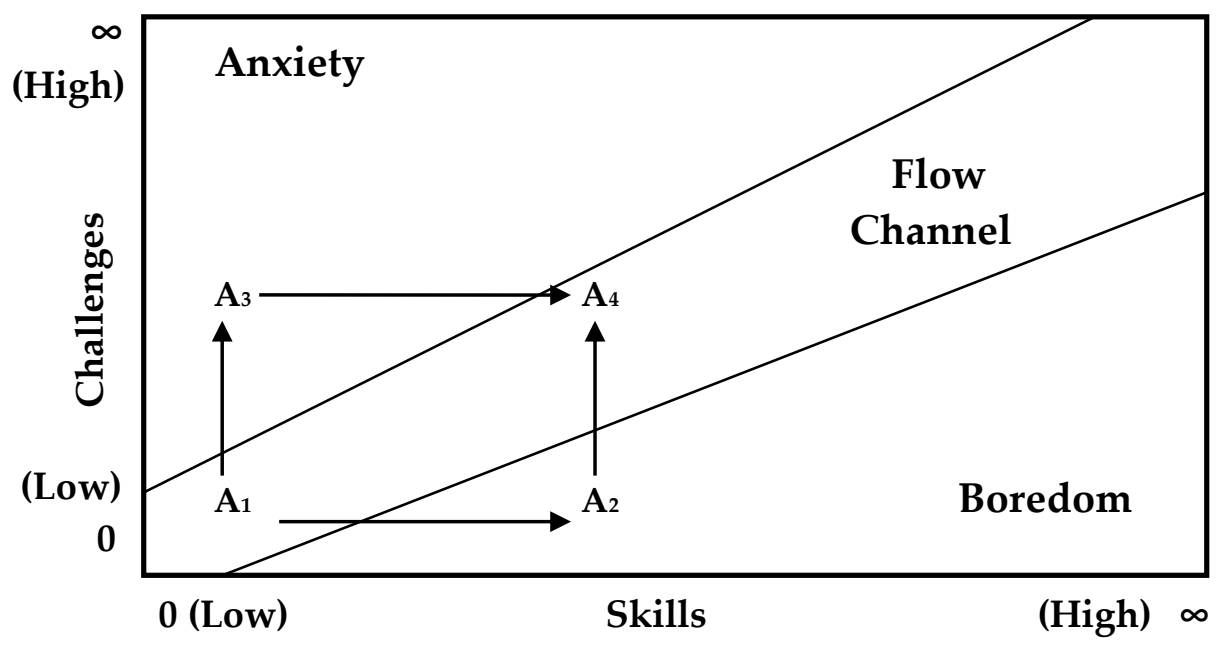

However the new model predicts flow only when challenges and skills are relatively in balance (Csikszentmihalyi, 2002, p. 252).

Hendry and Kloep's (2002) lifespan model of development also explores the interaction between life challenges and personal resources. Their theory is based on five key principles:

1) To stimulate development, individuals need challenge.

2) Successful solving of the challenge leads to development.

3) If a challenge is not solved, this will lead to problems in meeting future challenges.

4) The process of solving challenges is "an interactional, dialectical process" (p. 16) that leads to changes in the individual and/or the environment and accordingly stimulates development.

5) Individuals will have differing levels of resources to meet the challenges.

Although this theory is not directly linked to wellbeing, it reflects dynamic equilibrium theory in terms of challenges that an individual faces and in terms of how wellbeing is a fluctuating state. It also links to Cummins' idea of a homeostasis defensive range in terms of the resource pool that Hendry and Kloep discuss.

\section{A new definition of wellbeing}

The concept of wellbeing is undeniably complex, considering the aspects previously discussed. This paper has highlighted the difficulty that researchers have had with defining wellbeing but it has also recognised that previous research has been driven by dimensions and descriptions rather than definitions. In order to move closer to a new definition of wellbeing, therefore, this paper has focused on three key areas: the idea of a set point for wellbeing; the inevitability of 
equilibrium/homeostasis; and the fluctuating state between challenges and resources. Consequently, we would like to propose a new definition of wellbeing as the balance point between an individual's resource pool and the challenges faced:

Figure 4. Definition of Wellbeing

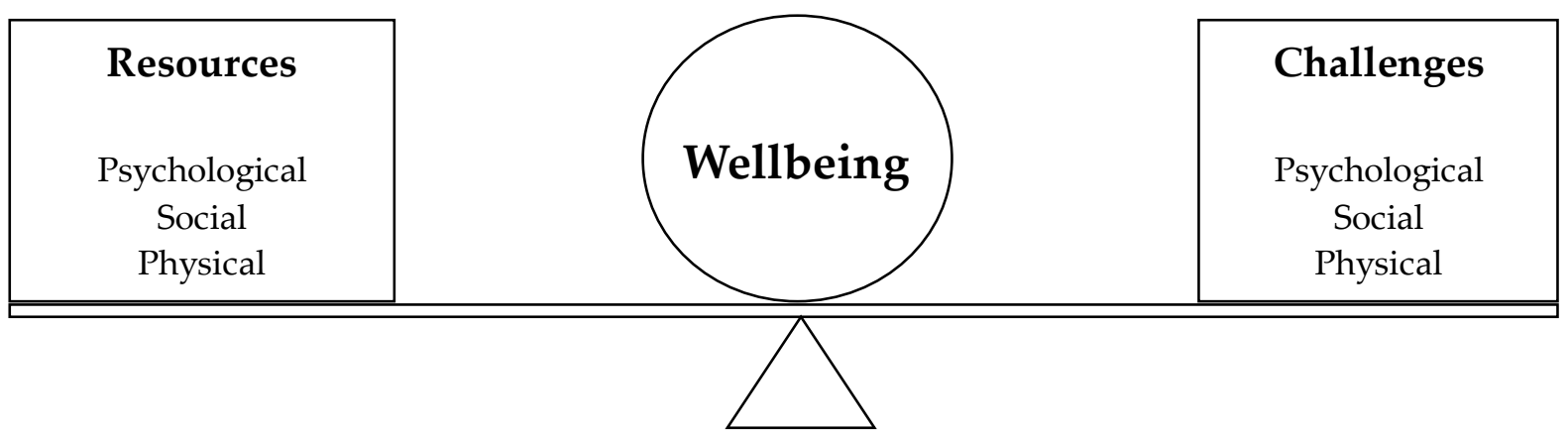

The see-saw represents the drive of an individual to return to a set-point for wellbeing (Brickman and Campbell, 1971; Headey and Wearing 1989, 1991, 1992) as well as the individual's need for equilibrium or homeostasis (Herzlich, 1973; Cummins, 2010). Now, however, the stocks and flows of Headey and Wearing (1992) have been replaced by the resources and challenges of Hendry and Kloep (2002) and are the elements that can affect the individual's equilibrium; tipping the see-saw from side to side, supporting Csikszentmihalyi's (2002) updated concept of 'flow'. This works just as Kloep, Hendry and Saunders (2009) described:

Each time an individual meets a challenge, the system of challenges and resources comes into a state of imbalance, as the individual is forced to adapt his or her resources to meet this particular challenge (p. 337).

In essence, stable wellbeing is when individuals have the psychological, social and physical resources they need to meet a particular psychological, social and/or physical challenge. When individuals have more challenges than resources, the see-saw dips, along with their wellbeing, and vice-versa.

The definition supports Headey and Wearing's (1992) aim to "understand how people cope with change and how their levels of well-being are affected" (p. 6). However, the proposed definition contradicts Cummins' idea of SWB being static when the individual is not challenged. Instead, we would argue, in line with Hendry and Kloep's theory, that a lack of challenge will lead to "stagnation" (Hendry \& Kloep, 2002), which will also affect the balance of the see-saw. The dynamic nature of the definition also reflects the viewpoint of Nic Marks, of the New Economics Foundation. He recently spoke of his interpretation of wellbeing on BBC Radio 4's Reasons to be cheerful:

Wellbeing is not a beach you go and lie on. It's a sort of dynamic dance and there's movement in that all the time and actually it's the functuality of that movement which actually is true levels of wellbeing (Nic Marks, Radio 4, 7 January 2012)

\section{The considered strengths of the new definition}

The authors of the current paper advocate that the vigour and freshness of this new proposed definition embraces a number of strengths: simplicity, universal application, optimism and basis for measurement. 


\subsection{Simplicity}

Firstly, the simple, yet precise nature of the definition answers Forgeard and colleagues' (2011) plea to move away from "broad definitions" (p. 81). As much as we are indebted to the work of Headey and Wearing (1992) and Cummins (2010), each of their models was complex and difficult to follow at first glance. Wellbeing has become a term used by the lay person, and is not just for the consideration of academics. Consequently, the authors believe that we have a duty to communicate what wellbeing is, in a clear and effective manner. Indeed, Lilienfeld (2012) talks in a forthright manner about the public's scepticism in regard to psychology and explains that we should be ready to communicate effectively when we "dare to venture outside of the hallowed halls of academia or our therapy offices to that foreign land called the 'real world'..." (p. 1). Consequently, we believe that the definition will be accessible in this forum.

\subsection{Universal application}

Secondly, a true asset of the definition is its universal nature. The definition can be applied to all individuals regardless of age, culture and gender. However, this universal nature does not reflect "a pronounced increase in the popularity of reductionist explanations of human behaviour" (Lilienfeld, 2012, p. 120) that has existed during the past several decades. Instead, it allows for the notion that each individual has a unique resource pool which "determines whether or not a task an individual meets turns out to be a routine chore, a challenge ... or a risk" (Hendry \& Kloep, 2002, p. 24).

\subsection{Optimism}

The definition also reflects the current emphasis on positive psychology. It views individuals "as decision makers, with choices, preferences, and the possibility of becoming masterful, efficacious" (Seligman, 2002b, p. 3). In a similar vein, Csikszentmihalyi (2002) makes it clear that "happiness is not something that just happens ... [it] is a condition that must be prepared for, cultivated, and defended privately by each person" (p. 2). This puts the pursuit of wellbeing in the hands of individuals by teaching them that they can increase their resources or challenges to maintain a sense of equilibrium. As well as reflecting this new direction in psychology, it also echoes current trends within the National Health Service in the UK with the Expert Patient Programme (EPP) that was launched in 2002. This programme supports the idea of self-management: "whatever we do to make the most of our lives by coping with our difficulties and making the most of what we have" (Martyn, 2002, p. 4).

\subsection{Basis for measurement}

Finally, the proposed definition answers a number of the concerns expressed at the start of this paper. With wellbeing becoming tangible (Thomas, 2009, p. 11) and operationalised, measurement becomes easier. This would extend the qualitative work undertaken by Hendry and Kloep (2002) on resources and challenges with the potential for developing a quantitative measure of wellbeing based on these two aspects and adds to the theoretical ideas already reviewed in this paper.

The authors have already used the definition to develop a new wellbeing questionnaire that is currently being applied in a Further Education setting. This questionnaire was developed through focus groups that explored the challenges faced by students aged 16-18, and the level of resources they felt they currently had to deal confidently with these challenges. The questionnaire is helping students to identify for themselves what resources need further 
development in order to maintain a stable level of wellbeing and it will be supported by a newly designed pastoral programme. Although our current research is being undertaken in an educational location, if our proposed definition is accepted as a valid definition of wellbeing the questionnaire could easily be adapted and applied across a wide range of settings.

To conclude, the publishing of this definition is timely given the intention of the UK government to implement measures of wellbeing for the UK as a whole. Indeed, the Office of National Statistics recently opened a discussion paper on domains and measures of national wellbeing (Beaumont, 2011). The paper states that the question of individual wellbeing "is an area which the national debate showed was important to people" (Beaumont, 2011, p. 4) and which has consequently been placed at the heart of the national wellbeing framework. We believe that using the proposed definition of wellbeing could aid the measurement of national wellbeing and further the understanding of wellbeing as a whole.

\author{
Authors \\ Rachel Dodge \\ Cardiff Metropolitan University \\ radodge@cardiffmet.ac.uk \\ Annette P. Daly \\ Cardiff Metropolitan University \\ Jan Huyton \\ Cardiff Metropolitan University \\ Lalage D. Sanders \\ Cardiff Metropolitan University
}

\title{
Publishing Timeline
}

Received 14 January 2012

Accepted 22 April 2012

Published 29 August 2012

\section{References}

Alkire, S. (2002). Dimensions of human development. World Development, 30, 181-205. http://dx.doi.org/10.1016/S0305-750X(01)00109-7

Beaumont, J. (2011). Measuring national well-being - Discussion paper on domains and measures. Newport: Office for National Statistics.

Bradburn, N. (1969). The structure of psychological well-being. Chicago: Aldine.

Brickman, P. D., \& Campbell, D. T. (1971). Hedonic relativism and planning the good society. In M.H. Appleby (Ed.), Adaptation-level Theory (pp. 287-302). New York: Academic Press.

Christopher, J. (1999). Situating psychological well-being: Exploring the cultural roots of its theory and research. Journal of Counselling \& Development, 77, 141-152. http://dx.doi.org/10.1002/j.15566676.1999.tb02434.x

Csikszentmihalyi, M. (1975). Beyond boredom and anxiety. San Francisco. Jossey-Bass.

Csikszentmihalyi, M. (2002). Flow: The Classic work on how to achieve happiness. London: Rider Books

Cummins, R. (1995). On the trail of the gold standard for life satisfaction. Social Indicators Research, 35, 179-200. http://dx.doi.org/10.1007/BF01079026

Cummins, R. (1998). The second approximation to an international standard of life satisfaction. Social Indicators Research, 43, 307-334. http://dx.doi.org/10.1023/A:1006831107052 
Cummins, R. (2010). Subjective wellbeing, homeostatically protected mood and depression: A Synthesis. Journal of Happiness Studies, 11, 1-17. http://dx.doi.org/10.1007/s10902-009-9167-0

Diener, E. (1984). Subjective well-being. Psychological Bulletin, 95, 542-575. http://dx.doi.org/10.1037/00332909.95.3.542

Diener, E. (2009). Subjective well-being. In E. Diener (Ed.), The science of well-being (pp. 11-58): New York: Spring.

Diener, E., Suh, M., Lucas, E., \& Smith, H. (1999). Subjective well-being: Three decades of progress. Psychological Bulletin, 125(2), 276-302. http://dx.doi.org/10.1037/0033-2909.125.2.276

Diener, E., \& Suh, E. (1997). Measuring quality of life: Economic, social, and subjective indicators. Social Indicators Research, 40 (1-2), 189-216. http://dx.doi.org/10.1023/A:1006859511756

Duckworth, A. L., Steen, T. A., \& Seligman, M. E. P. (2005). Positive psychology in clinical practice. Annual Review of Clinical Psychology, 629-651. http://dx.doi.org/10.1146/annurev.clinpsy.1.102803.144154

Emerson, E. (1985). Evaluating the impact of deinstitutionalization on the lives of mentally retarded people. American Journal of Mental Deficiency, 90(3), 277-288.

Felce, D. \& Perry, J. (1995). Quality of life: Its definition and measurement. Research in Developmental Disabilities, 16(1), 51-74. http://dx.doi.org/10.1016/0891-4222(94)00028-8

Foresight Mental Capital and Wellbeing Project (2008). Final Project report. The Government Office for Science, London.

Forgeard, M. J. C., Jayawickreme, E., Kern, M. \& Seligman, M. E. P. (2011). Doing the right thing: Measuring wellbeing for public policy. International Journal of Wellbeing, 1(1), 79-106. http://dx.doi.org/10.5502/ijw.v1i1.15

Gable, S. L., \& Haidt, J. (2005). What (and why) is positive psychology? Review of General Psychology, 9, 103-110. http://dx.doi.org/10.1037/1089-2680.9.2.103

Griffin, J. (1986). Well-Being: Its meaning, measurement and moral importance. Oxford: Clarendon Press.

Headey, B. W. (2006). Happiness: Revising set point theory and dynamic equilibrium theory to account for long term change. Berlin: DIW German Institute for Economic Research.

Headey, B. W., \& Wearing, A. J. (1989). Personality, life events and subjective well-being: Toward a dynamic equilibrium model. Journal of Personality and Social Psychology, 57, 731-739. http://dx.doi.org/10.1037/0022-3514.57.4.731

Headey, B. W., \& Wearing, A. J. (1991). Subjective well-being: a stocks and flows framework. In Strack, F., Argyle, M., \& Schwarz, N. (Eds.). Subjective Wellbeing - An interdisciplinary perspective (pp. 49-76). Oxford: Pergamon Press.

Headey, B. W., \& Wearing, A. J. (1992). Understanding happiness: A theory of subjective well-being. Melbourne: Longman Cheshire.

Headey, B. W., Holmstrom, E., \& Wearing, A. J. (1984a). The impact of life events and changes in domain satisfactions on well-being. Social Indicators Research, 15, 203-227. http://dx.doi.org/10.1007/BF00668671

Headey, B. W., Holmstrom, E., \& Wearing, A. J. (1984b). Well-being and ill-being: Different dimensions? Social Indicators Research, 14, 115-139. http://dx.doi.org/10.1007/BF00293406

Hendry, L. B., \& Kloep, M. (2002). Lifespan development: Resources, challenges and risks. London: Thomson Learning.

Herzlich, C. (1973). Health and Illness - A social psychological analysis. London: Academic Press.

Hursthouse, R. (1999). On virtue Ethics. Oxford: Oxford University Press.

James, W. (1988). Writings 1902-1910. New York: Library of America.

Joseph, S. \& Wood, A. (2010). Assessment of positive functioning in clinical psychology: Theoretical and practical issues. Clinical Psychology Review, 30, 830-838. http://dx.doi.org/10.1016/j.cpr.2010.01.002

Kahneman, D., Diener, E. \& Schwarz, N. (1991). Foundations of hedonic psychology: Scientific perspectives on enjoyment and suffering New York: Russell Sage Foundation.

Kahneman, D., Diener, E., \& Schwarz, N. (Eds.) (1999). Well-being: Foundations of hedonic psychology. New York: Russell Sage Foundation Press. 
Keyes, C. (2002). The mental health continuum: From languishing to flourishing in life. Journal of Health and Behaviour Research, 43, 207-222. http://dx.doi.org/10.2307/3090197

Keyes, C. (2005). Mental illness and/or mental health? Investigating axioms of the complete state model of health. Journal of Consulting and Clinical Psychology, 73(3), 539-548. http://dx.doi.org/10.1037/0022006X.73.3.539

Keyes, C. (2009). The nature and importance of positive mental health in America's adolescents. In Gilman, R., Huebner, E., \& Furlong, M. (Eds.). Handbook of positive psychology in schools. New York: Routledge.

Keyes, C. L. M., Shmotkin, D., \& Ryff, C. D. (2002). Optimizing well-being: The empirical encounter of two traditions. Journal of Personality and Social Psychology, 82, 1007-1022. http://dx.doi.org/10.1037/0022-3514.82.6.1007

Kloep, M., Hendry, L., \& Saunders, D. (2009) A new perspective on human development. Conference of the International Journal of Arts and Sciences, 1(6), 332-343.

Lee, W., \& Oguzoglu, O. (2007). Well-being and ill-being: A bivariate panel data analysis. Discussion paper Institute for the Study of Labor.

Lilienfeld, S. O. (2012). Public skepticism of psychology: Why many people perceive the study of human behavior as unscientific. American Psychologist, 67(2), 111-129. http://dx.doi.org/10.1037/a0023963

Linley, P. A., \& Joseph, S. (Eds.) (2004). Positive psychology in practice. Hoboken, NJ: John Wiley \& Sons, Inc.

Linley, P. A., Joseph, S., Harrington, S., \& Wood, A. M. (2006). Positive psychology: Past, present, and (possible) future. Journal of Positive Psychology, 1, 3-16. http://dx.doi.org/10.1080/17439760500372796

Lyubomirsky, S., \& Lepper, H. S. (1999). A measure of subjective happiness: Preliminary reliability and construct validation. Social Indicators Research, 46, 137-155. http://dx.doi.org/10.1023/A:1006824100041

Martyn, D. (2002). The experiences and views of self-management of people with a schizophrenia diagnosis. London: Rethink.

Michaelson, J., Abdallah, S., Steuer, N., Thompson, S., \& Marks, N. (2009). National accounts of well-being: Bringing real wealth onto the balance sheet. London: New Economics Foundation.

Morrow, V., \& Mayall, B. (2009). What is wrong with children's well-being in the UK? Questions of meaning and measurement. Journal of Social Welfare and Family Law, 31(3), 217-229. http://dx.doi.org/10.1080/09649060903354522

Nussbaum, M. (2000). Women and human development: The capabilities approach. Cambridge: Cambridge University Press.

Ormel, J., \& Schaufeli, W. (1991). Stability and change of psychological distress and their relationship with self-esteem and locus of control. Journal of Personality and Social Psychology, 60, 288-299. http://dx.doi.org/10.1037/0022-3514.60.2.288

Ormel, J. \& Wohlfarth, T. (1991). How neuroticism, long-term difficulties, and changes in quality of life affect psychological distress. A longitudinal approach. Journal of Personality and Social Psychology, 60, 744-755. http://dx.doi.org/10.1037/0022-3514.60.5.744

Pollard, E., \& Lee, P. (2003). Child well-being: a systematic review of the literature, Social Indicators Research, 61(1), 9-78. http://dx.doi.org/10.1023/A:1021284215801

Reber, A. (1995). Dictionary of psychology - Second Edition. Harmonsworth: Penguin.

Rees, G., Goswami, H., \& Bradshaw, J. (2010). Developing an index of children's subjective well-being in England: Summary Report. The Children's Society, London.

Rogers, C. (1961). On becoming a person. Boston: Houghton Mifflin.

Ryff, C. D. (1989a). Happiness is everything, or is it? Explorations on the meaning of psychological wellbeing. Journal of Personality and Social Psychology, 57, 1069-1081. http://dx.doi.org/10.1037/0022$\underline{3514.57 .6 .1069}$

Ryff, C. D. (1989b). Beyond Ponce de Leon and life satisfaction: New directions in quest of successful ageing. International Journal of Behavioral Development, 12, 35-55.

http://dx.doi.org/10.1177/016502548901200102

Ryff, C., \& Keyes, C. (1995). The structure of psychological well-being revisited. Journal of Personality and Social Psychology 69(4), 719-727. http://dx.doi.org/10.1037/0022-3514.69.4.719 
Ryff, C., \& Singer, B. (2008). Know thyself and become what you are: An eudiamonic approach to psychological wellbeing. Journal of Happiness Studies, 9, 13-39. http://dx.doi.org/10.1007/s10902-0069019-0

Seligman, M. E. P. (2002a). Authentic happiness: Using the new positive psychology to realize your potential for lasting fulfilment. London: Nicholas Brealey Publishing.

Seligman, M. E. P. (2002b). Positive psychology, positive prevention, and positive therapy. In Snyder. C. R., \& Lopez. S. (Eds.). Handbook of positive psychology (pp. 3-13). New York: Oxford University Press.

Seligman, M. E. P. (2011). Flourish - A new understanding of happiness and well-being - and how to achieve them. London: Nicholas Brealey Publishing.

Shah, H., \& Marks, N. (2004). A well-being manifesto for a flourishing society. London: The New Economics Foundation

Shin, D., \& Johnson, D. (1978). Avowed happiness as an overall assessment of the quality of life. Social Indicators Research, 5(1), 475-492. http://dx.doi.org/10.1007/BF00352944

Singh, K., \& Duggal Jha, S. (2008). Positive and negative affect, and grit as predictors of happiness and life satisfaction. Journal of the Indian Academy of Applied Psychology, 34, 40-45.

Stiglitz, J., Sen, A., \& Fitoussi, J. P. (2009). Report by the commission on the measurement of economic performance and social progress.

Stratham, J., \& Chase, E. (2010). Childhood wellbeing - A brief overview. Loughborough: Childhood Wellbeing Research Centre.

Suh, E., Diener, E., \& Fujita, F. (1996). Events and subjective well-being: Only recent events matter. Journal of Personality and Social Psychology, 70(5), 1091-1102. http://dx.doi.org/10.1037/00223514.70.5.1091

Sumner, L. W. (1996). Welfare, happiness and ethics. Oxford: Clarendon Press.

Thomas, J. (2009). Working paper: Current measures and the challenges of measuring children's wellbeing. Newport: Office for National Statistics.

Wallis, C. (2005). The new science of happiness. Time Sunday 9th January. http://www.time.com/time/printout/0,8816,1015902,00.html\#.

Waterman, A. S. (1993). Two conceptions of happiness: Contrasts of personal expressiveness (eudaimonia) and hedonic enjoyment. Journal of Personality and Social Psychology, 64(4), 678-691. http://dx.doi.org/10.1037/0022-3514.64.4.678

World Health Organization. (1997). WHOQOL Measuring Quality of Life. Geneva: World Health Organisation.

Zikmund, V. (2003). Health, well-being, and the quality of life: Some psychosomatic reflections. Neuroendocrinology Letters, 2(6), 401-403. 